\title{
Documenting Cultures of Harassment in Archaeology: A Review and Analysis of Quantitative and Qualitative Research Studies
}

\begin{abstract}
Barbara L. Voss
This article is the first of a two-part series to analyze current research on harassment in archaeology. Harassment has shaped the discipline of archaeology since at least the late 1800s. Since the 1970s, harassment has been recognized as a significant factor impacting gender equity in archaeology. Recent qualitative and quantitative research has verified that harassment occurs at epidemic rates in archaeology. Archaeologists are primarily harassed by other archaeologists, and harassment occurs not only in field research settings but also in classrooms, laboratories, museums, office workplaces, and conferences. Although women in archaeology experience a higher frequency of harassment, both men and women report harassment at disturbingly high rates. Archaeologists of color, LGBTQIA+ archaeologists, nonbinary archaeologists, and archaeologists with disabilities are also disproportionately harassed. As reflected in the author's own career experiences, harassment creates a cognitive burden for survivors and reduces access to professional opportunities, directly impacting diversity within archaeology. Fortunately, there are evidence-based interventions and policies that can reduce harassment and support survivors. These are discussed in the second article, "Disrupting Cultures of Harassment in Archaeology."
\end{abstract}

Keywords: harassment in archaeology, discrimination, equity, means of prevention

Este artículo es el primero de una serie de dos partes que analiza las investigaciones actuales sobre el acoso en arqueología. El acoso ha dado forma a la disciplina arqueológica desde, al menos, finales del siglo XIX. Desde la década de 1970, el acoso ha sido reconocido como un factor significativo que afecta la equidad de género en arqueología. Investigaciones cualitativas y cuantitativas recientes han comprobado que el acoso ocurre en tasas epidémicas dentro de esta disciplina. Lxs arqueólogxs son acosadxs principalmente por otrxs arqueólogxs. El acoso ocurre no solo en entornos de investigación de campo, sino también en aulas, laboratorios, museos, oficinas y conferencias. Si bien una mayor frecuencia de mujeres son acosadas en arqueología, tanto hombres como mujeres denuncian acoso a tasas inquietantemente altas. Lxs arqueólogxs de color, lxs arqueólogxs LGBTQIA +, lxs arqueólogxs no binarios y lxs arqueólogxs con discapacidades también son acosados de manera desproporcionada. Como se refleja en las propias experiencias profesionales de la autora, el acoso crea una carga cognitiva para los sobrevivientes y reduce el acceso a oportunidades profesionales, lo que impacta directamente en la diversidad dentro de la arqueología. Afortunadamente, existen intervenciones y políticas basadas en evidencia que pueden reducir el acoso y apoyar a los sobrevivientes. Estos últimos serán analizados en el segundo artículo, "La disrupción de las culturas del acoso en la arqueología."

Palabras clave: hostigamiento e acoso en arqueología, discriminación, equidad, medios de prevención

[Content advisory: This article discusses harassment and discrimination in archaeology, including accounts of sexual assault.]
I am a survivor of harassment and sexual assault in archaeology. And I am one of many. Over the past decade, researchers,

Barbara L. Voss (bvoss@ stanford.edu, corresponding author) — Department of Anthropology, Stanford University, 450 Jane Stanford Way, Stanford, CA 94304-2034, USA

\section{American Antiquity 86(2), 2021, pp. 244-260}

Copyright $($ ) The Author(s), 2021. Published by Cambridge University Press on behalf of the Society for American Archaeology. This is an Open Access article, distributed under the terms of the Creative Commons Attribution-NonCommercialNoDerivatives licence (http://creativecommons.org/licenses/by-nc-nd/4.0/), which permits non-commercial re-use, distribution, and reproduction in any medium, provided the original work is unaltered and is properly cited. The written permission of

Cambridge University Press must be obtained for commercial re-use or in order to create a derivative work.

doi:10.1017/aaq.2020.118 
activists, and survivors ${ }^{1}$ have spoken publicly about what was always an open secret: that archaeologists experience harassment and assault at epidemic rates (Table 1), that this abusive behavior is primarily perpetrated by other archaeologists, and that perpetrators are rarely held accountable for their actions.

Harassment is a problem that affects all archaeologists. It has reduced the diversity of our discipline by driving some researchers away from specific areas and topics, and by pushing others out of the field altogether. Consequently, harassment not only affects individual archaeologists but also shapes archaeological research and our interpretations of the past. Harassment is not just caused by a few bad actors. It is enabled by structural conditions and disciplinary culture. The good news is that there are straightforward best practices that can reduce harassment in archaeology and diminish its negative effects. These evidence-based measures are discussed in the second article in this series, "Disrupting Cultures of Harassment in Archaeology" (Voss 2021).

\section{What Is Harassment?}

In the United States, the term "sexual harassment" refers to a wide range of discriminatory and illegal practices related to actual or perceived gender identity and sexual orientation, as well as to unwanted sexual advances, quid pro quo coercions, hostile environments, and sexual assaults that occur in educational and workplace environments. In both legal and research contexts, most people tend to distinguish between nonphysical and physical harassment. Nonphysical harassment includes verbal and nonverbal behaviors that convey hostility, objectification, exclusion, or second-class status based on the perceived gender or sexual orientation of the person being targeted. Some harassing content is discriminatory, such as statements about one gender being unsuited to certain kinds of work. Other harassment is sexually focused, including leering; making sexual gestures; displaying sexually suggestive objects or images; making or using derogatory comments, epithets, slurs, and jokes; making graphic verbal commentaries about an individual's body; and using sexually degrading words to describe an individual (California
Department of Fair Employment and Housing 2020). Physical harassment includes "unwanted sexual contact, or sexual contact in which they could not or did not give consent, or felt it would be unsafe to fight back or not give consent" (Clancy et al. 2014:4). Both nonphysical and physical harassment can be involved in sexual coercion, in which "favorable professional or educational treatment is conditioned" on acceptance of sexual attention, or when a harasser makes or threatens "retaliatory action after receiving a negative response to sexual advances" (California Department of Fair Employment and Housing 2020).

Both physical and nonphysical harassment can take the form of "put-downs" and "come-ons" (Clancy 2018). Put-downs are acts—such as sexist, racist, or homophobic comments or gesturesthat stigmatize targeted individuals according to their actual or perceived identity. Come-ons are unwanted sexual advances, such as verbal pressure to enter an intimate relationship, unwanted touching, quid pro quo proposals, and sexual assault. These two aspects are interrelated, and many acts of harassment involve both identity-based stigmatization and unwanted sexual advances.

One of the most important findings of recent research is that nonphysical harassment "can result in the same level of negative professional and psychological outcomes as . . instances of sexual coercion" (National Academies of Sciences, Engineering, and Medicine 2018). Consequently, although it is useful to distinguish between physical and nonphysical harassment for research purposes, it would be a mistake to assume that one is more or less severe than the other. Verbal and visual harassment can generate hostile work and educational environments, and both forms are also recognized as grooming behaviors that increase targets' vulnerability to physical abuse (Johnson et al. 2018:2).

All types of harassment can be direct or indirect. Direct harassment refers to situations where one person's actions are targeting another person. Indirect harassment occurs when someone is affected by behavior that may not be directly targeting that person. Overhearing discriminatory or sexually degrading language, being in a work environment where offensive images are displayed, and witnessing harassment 
Table 1. Prevalence of Harassment in Archaeology.

\begin{tabular}{|c|c|c|c|c|c|c|c|c|c|}
\hline \multirow[b]{2}{*}{ Research Study } & \multirow[b]{2}{*}{ Population } & \multirow[b]{2}{*}{$N$} & \multirow[b]{2}{*}{$\begin{array}{l}\text { Type of Harassment } \\
\text { (subgroup) }\end{array}$} & \multicolumn{6}{|c|}{ Frequency of Study Participants Reporting Harassment (\%) } \\
\hline & & & & Men & Women & Nonbinary & LGBTQIA+ & $\begin{array}{l}\text { People of Color / } \\
\text { Ethnic Minority }\end{array}$ & $\begin{array}{l}\text { People with } \\
\text { Disabilities }\end{array}$ \\
\hline \multirow{2}{*}{$\begin{array}{l}\text { Survey of } \\
\quad \text { Academic Field Experiences }{ }^{\mathrm{a}}\end{array}$} & \multirow{2}{*}{$\begin{array}{l}\text { Field researchers } \\
\qquad(23.9 \% \text { archaeologists })\end{array}$} & \multirow[t]{2}{*}{666} & Nonphysical & 40.0 & 70.0 & & & & \\
\hline & & & Sexual assault & 6.0 & 26.0 & & & & \\
\hline \multirow{2}{*}{$\begin{array}{l}\text { Southeastern Archaeological } \\
\text { Conference }^{\mathrm{b}}\end{array}$} & \multirow{2}{*}{$\begin{array}{l}\text { Southeastern Archaeological } \\
\text { Conference membership }\end{array}$} & \multirow[t]{2}{*}{382} & Nonphysical & 46.0 & 75.0 & & & & \\
\hline & & & Unwanted sexual contact & 8.0 & 15.0 & & & & \\
\hline \multirow{4}{*}{$\begin{array}{l}\text { Gender Equality and } \\
\text { Sexual Harassment }\end{array}$} & Society for California & \multirow[t]{4}{*}{454} & Verbal (students) & 23.0 & 44.0 & & 61.0 & 44.0 & \\
\hline & \multirow{3}{*}{ Archaeology membership } & & Physical (students) & 6.0 & 20.0 & & 32.0 & 15.0 & \\
\hline & & & Verbal (professionals) & 19.0 & 51.0 & & 48.0 & 49.0 & \\
\hline & & & Physical (professionals) & 5.0 & 19.0 & & 14.0 & 26.0 & \\
\hline Acoso Sexual en Archaeología ${ }^{d}$ & Archaeologists in Spain & 321 & Nonphysical and physical & 15.0 & 51.0 & & & & \\
\hline Fieldwork Experiences ${ }^{\mathrm{e}}$ & Archaeologists (international) & 300 & Nonphysical and physical & 14.8 & 33.6 & 100.0 & 42.4 & 23.5 & 47.5 \\
\hline Archaeology in Canada ${ }^{\mathrm{f}}$ & Archaeologists in Canada & 315 & Sexual harassment & 16.0 & 78.0 & & & & \\
\hline \multirow{3}{*}{$\begin{array}{l}\text { Equity and Diversity in } \\
\text { Canadian Archaeology }\end{array}$} & \multirow[t]{3}{*}{ Archaeologists in Canada } & \multirow[t]{3}{*}{564} & Verbal & 49.7 & 66.5 & & & & \\
\hline & & & Unwanted touching & 4.1 & 21.7 & & & & \\
\hline & & & Sexual violence / assault & 2.7 & 6.3 & & & & \\
\hline
\end{tabular}

${ }^{a}$ Clancy et al. 2014.

b Meyers et al. 2015, 2018.

${ }^{c}$ Radde 2018; VanDerwarker et al. 2018.

${ }^{\mathrm{d}}$ Coto Sarmiento et al. 2018.

${ }^{\mathrm{e}}$ Bradford et al. 2019.

${ }^{\mathrm{f}}$ Jalbert 2019.

${ }^{\mathrm{g}}$ Hodgetts et al. 2020. 
of someone else are all examples of indirect harassment. Additionally, indirect harassment can include situations in which a supervisor or gatekeeper creates a biased learning or work environment by showing favoritism to someone else based on an actual or desired romantic or sexual relationship.

Harassment and bullying are sometimes used interchangeably. Both involve hurtful or harmful behaviors that involve an imbalance of power, often in a context where the target has difficulty stopping the harmful actions directed at them. Harassment occurs when the unwanted behaviors are connected to the target's identity: gender, sexual orientation, age, race, ethnicity, national origin, class background, queerness, and/or disability. Increasingly, the term "identity-based harassment" is used to encompass this wide range of discriminatory and predatory behaviors.

For this article, I use the broad term "harassment" in recognition that gender and sexuality are not the sole factors in professional abuses of power. Although most of the commentary on harassment in archaeology has focused on the "male perpetrator, female victim" dynamic, recent studies have shown that significant numbers of men are also harassed. Notably, archaeologists of color, LGBTQIA $+{ }^{2}$ archaeologists, and archaeologists with disabilities report harassment at much higher rates than white, heterosexual, and cisgender archaeologists.

\section{Personal Testimony: What Happened to Me}

"What works best is when men dig and women do the screening." "How can you [dig/screen] with those [slang for 'breasts'] in the way?" "How do you know you're really a lesbian if you haven't slept with me [a man] yet?"

When I began my career in archaeology 35 years ago, comments like these were so prevalent on field sites that I came to expect them. As Heath-Stout (2019:286) observes, the prevalence of sexual harassment and assault has "shaped the culture of the field, and led some archaeologists to see weathering harassment as a kind of price of entry for . . . doing archaeological work."

Survivors' accounts have been central to the decades-long fight to raise awareness about harassment in archaeology by making "the open secrets a little less secretive" and providing "an important tool for confronting social injustice and instigating social change" (Collective Change 2019:13). Still, I hesitated to include my own experience in this article. Like many other targets of harassment, I have "fear about being shamed or accused, [and] anxiety about losing credibility and respect" (Ross 2015:180). As Mahmood (2009) explained in her essay about being raped during ethnographic field research, "After all, I don't want to be viewed as a victim."

But not wanting to be viewed as a victim has also meant distancing myself from other archaeologists who have given public testimony about their experiences as targets of harassment and assault. With few exceptions, it has been the most vulnerable members of our professionstudents, trainees, and entry-level professionalswho have reported their experiences and demanded accountability from employers, universities, and professional societies. As a senior archaeologist, I want to publicly share the psychological and professional risks of being identified as a survivor and contribute a long-term career perspective to these testimonies.

As will be detailed later in this article, many studies omit information about the race, sexuality, and class of both victims and perpetrators. To contextualize my personal narrative, I am a white, queer, middle-class archaeologist, and the people who harassed me were also white and-to all appearances-middle-class. Along with my current role as a university professor, my 35-year career in archaeology includes undergraduate, master's, and doctoral training; entry- and supervisorlevel roles in private-sector cultural resource management; employment in and collaboration with several museums; contracts and partnerships with government agencies, Native American tribes, community heritage organizations, and environmental consulting firms; and participation in and service to professional archaeological societies. In sharing my personal experiences, I have chosen to not name individuals, institutions, or projects. I have used context-neutral rank-based termssuch as "trainee," "colleague," "supervisor," "project director," and "gatekeeper"- to describe the positions held by me, harassers, and bystanders at the time of the events. I ask that readers refrain from speculating about the specific people or 
projects involved in these incidents in order to keep the focus on the structural conditions that enable and perpetuate these abuses of power.

\section{In the Field}

When I entered archaeology as a trainee, I was surprised by the rampant sexual banter on field sites and in laboratories. On one project, my supervisor's favorite gag was to hold up a recently excavated pestle or other elongated stone and then ask me what I thought of the "sq--- pleaser." I did not understand what he meant until a senior colleague explained that the supervisor was implying the artifacts were shaped like dildos. When I pretended I had not heard these racist and sexist "jokes," my supervisor repeated himself louder and louder until I faked a laugh.

Early in my career, I was almost always the only "out" queer person on field projects. I felt a lot of pressure to "be one of the boys," and this led to poor decisions on my part, such as trying to match other colleagues drink for drink, joining in sexualized banter, and pretending not to be bothered by pornography. On one project, a supervisor who had previously made harassing comments invited me to join him and several other team members to see a hard-core porn movie in an adult theater in the nearby city. Feeling desperate to belong, I accepted, only to be ridiculed throughout and afterward. Looking back, it is easy to see how these attempts to "fit in" always backfired, exposing me to further harassment and unwanted sexual attention. But as a young and inexperienced trainee, I did not know what to expect or how to navigate the sexism and homophobia commonly present in field research settings.

Although I have worked with many kind and compassionate supervisors, I also learned that I could not always count on them to prioritize my well-being. On one project, a colleague exposed himself to me in the shower facility. Another night, while drunk, he tried to barge in on me when I was in the toilet. When I mentioned his behavior to my supervisor, she interrupted me to praise this colleague's important technical skills. She said that she had no idea how she would be able to complete the project without him. The message was clear: my colleague's skills were more important to my supervisor than my safety.
Once, while traveling to a new project, I had been given instructions to go by bus to an isolated town near the field project, where I was to use a public telephone to call my supervisor for a ride to the site. But when I arrived at the town and called my supervisor, no one answered. I called repeatedly with no luck. In those pre-cell-phone days, I did not have a way of contacting anyone else for help. When night fell, the bus driver, who had insisted on staying with me at the bus station, called people he knew to drive me to the site. Three men arrived in a car a few minutes later, and the bus driver loaded my luggage into the car trunk and then led me to the car's backseat. I was sandwiched in the backseat between two of the men, with the third driving the car.

Within a few minutes of leaving the bus station, the two men in the backseat started to assault me sexually. As we drove on dark country roads, I had no way of knowing where we were and no way to get out of the vehicle. I lost track of time; it might have been one hour or several before we finally arrived at the field site. Dazed, I stumbled out of the car while one of my assaulters took my bags from the trunk and placed them on the ground. After the three men drove away, I found my supervisor and told her what happened. She looked confused and said I probably had not tried hard enough to call her. She told me that I looked OK, said that obviously I had not been hurt, and said I should just get a good night's sleep. The next morning the project director came to talk to me. He told me that he had heard (presumably, from my supervisor) that I had a difficult experience the day before, but that he was relieved that I was all right. Then, he walked away.

I was not OK. I was not all right.

\section{In the Lab and Office}

My experiences with harassment in archaeology are not limited to fieldwork settings. In one job interview, I was asked about my relationship status and whether I planned to get pregnant anytime soon. Comments about my body and clothing - and other colleagues' bodies and clothing-as well as inappropriate questions about my sexual identity and sexual activity, were common in some labs and offices. In one setting, a supervisor began to make sexually 
explicit comments to me during our one-on-one meetings. She bragged about her strong sex drive and sexual skills. Once, boasting about the firmness of her breasts, she told me to touch them. When I refused, she reached forward, grabbed my wrist, and placed my hand on her chest. "Squeeze it and see," she demanded, laughing. I pulled back my hand without squeezing. Annoyed, she abruptly ended our meeting.

A few weeks later, I learned that this same supervisor was spreading rumors that I was having an extramarital affair with another colleague. Concerned that this gossip could affect my professional reputation, I spoke about the situation with another supervisor. He provided cover for me to discreetly shift my role so that I no longer needed to report directly to the abusive supervisor. But he also advised me to remain friendly and collegial with her because he thought that she would retaliate if she found out that I had complained.

\section{Today}

In my 35 years as a practicing archaeologist, the positive experiences have far outweighed the negative ones. Even on projects or in workplaces where I was harassed, the vast majority of my colleagues and supervisors have been compassionate and ethical people who neither condoned nor enabled harassment and abuse.

The security of my current position as a tenured university professor might give the impression that my career was not adversely affected by these experiences. To the contrary, stepping away from particular professional relationships often meant foregoing certain kinds of training, funding, and research opportunities. Like many other archaeologists who have been harassed (Meyers et al. 2018:281), twice I left archaeology altogether. It was not much better elsewhere, however. In service sector and front office jobs, I was pressured to feminize my appearance. In one nonarchaeology job, a supervisor showed me erotic drawings he had made of me and offered me extra money to have sex with him. I believe that at some point I decided unconsciously that if I was going to be harassed at work, at least in archaeology I was doing work that I loved.
As the research reviewed below demonstrates, harassers in archaeology most commonly target subordinates. Many of the incidents I have described did occur when I was a trainee or entrylevel archaeologist. I wish I could say that achieving seniority has completely protected me from harassment, but unfortunately, this is not the case. My professional visibility as a queer archaeologist continues to expose me to homophobic and transphobic harassment. Routinely, colleagues and students report to me that they were "warned" by other archaeologists about my sexual orientation. At a Society for American Archaeology (SAA) annual meeting only a few years ago, another archaeologist called hotel security when she encountered me in the restroom appropriate to my gender. The privilege of seniority and tenure, in my case, is significant: I no longer worry that I will lose my job because of identitybased harassment. And I now know that I belong in archaeology and that harassment is always the fault of the perpetrator.

\section{Activism and Research about Harassment in Archaeology}

Of course, I knew that I was not the only archaeologist who had been harassed in the course of studies and professional work. Whisper campaigns have long circulated information about supervisors, peers, and projects to be avoided. Paradoxically, this focus on "bad" people and "unsafe" projects drew attention away from the endemic frequency of harassment throughout the profession. In the past seven years, systematic research has revealed that harassment occurs at epidemic rates in archaeology and follows regular patterns related to the research setting, the identities and ranks of harassers and their targets, and the presence or absence of effective codes of conduct.

Most of the studies reviewed here analyzed harassment from the perspective of a male-female binary, and many did not disaggregate the information collected by race, class, sexual orientation, and ability. Noting that the North American archaeology community is overwhelmingly white, Leighton (2020:446) described her investigation as "implicitly a study of whiteness." Therefore, I have given extra attention to research and 
testimonies that address identities beyond binary gender and consider the impact of race, ethnicity, class, and disability.

\section{Gender Equity Research: Harassment as a Mechanism for Exclusion}

The fight against harassment in archaeology has deep roots stretching back to the founding of our discipline. In the United States, the first anthropological society (which included archaeologists) - the Anthropological Society of Washington (ASW) - excluded women completely from participation. In response, in 1885 , a group of women anthropologists-including archaeologists Mary Hemenway, Zelia Nuttall, Matilda Coxe Stevenson, and Alice Fletcherformed the Women's Anthropological Society of America (WASA). Their work became so influential that the ASW eventually solicited their involvement, inviting them to several joint meetings between 1893 and 1898 and eventually abandoning its men-only policy. In 1902, the two organizations merged into the American Anthropological Association (AAA; Lamb 1906; Levine 1994).

Members of WASA (and, later, of AAA) observed that women had much more difficulty entering archaeology than other branches of anthropology. The team-based nature of archaeology was recognized as the source of many barriers: archaeological "training is a matter of apprenticeship, and success depends crucially on being drawn into a research team where you can develop the expertise and credibility necessary" (Wylie 1994a :68-69). Historical research shows that women archaeologists during late 1800s and early to mid-1900s largely navigated these barriers through three strategies: independent wealth, the identification and occupation of niche roles, and partnerships and marriages with male archaeologists (Browman 2013; Levine 1994). This latter approach normalized intimate relationships as a pathway for women's access to archaeological sites, collections, and laboratories. In 1971, "The Female Anthropologist's Guide to Academic Pitfalls" was published anonymously in the AAA Anthropology Newsletter. The author sarcastically observed that, in order to be successful, female archaeologists should be "married to the field director, an ideal situation, and one devoutly to be recommended" (Anonymous 1994:8).

In the 1970s, the Civil Rights Act (passed in 1964, amended in 1972) and the Equal Employment Opportunity Act (1972) spurred archaeological professional societies to address equity issues systematically. In 1970, the Association of Black Anthropologists (originally, the Committee on Minority Participation) formed as an AAA section to "highlight situations of exploitation, oppression and discrimination" and to link anthropological theory "to struggles for social justice" (Association of Black Anthropologists 2020; see also Harrison 1987). The Society for Black Archaeologists, founded in 2011, continues and expands on this mission, including an explicit commitment to "addressing harassment, repatriation, and the concerns of LGBTQIA archaeologists" (Franklin et al. 2020:759).

Starting in the mid-1970s, various committees on the status of women in archaeology focused on the "pipeline problem" - the apparent lack of qualified women to compete on an equal footing for professional jobs in archaeology (Levine 1994; Tomásková 2008; Wylie 1993, 1994b). Yet, by the mid-1980s, women's significant gains in archaeology education were not mirrored in the job market, and "patterns of under-representation and job segregation ... could no longer be explained in terms of a pipeline problem" (Wylie 1993:213). Research and equity advocacy turned toward the "leaky pipeline": women archaeologists, with the same qualifications and experience as their male peers, were either leaving the field or holding lower-status and worse-paid positions. In a 1992 AAA Equity Workshop, participants identified harassment as a key factor that affected gender equity in archaeology (Nelson and Nelson 1994:233-234). Reports and publications that followed identified senior men harassing junior women as the most common pattern, but they also noted the presence of peer-to-peer, same-sex, junior-senior, and female-male harassment, as well as the heightened risks faced by LGBTQIA+ archaeologists and archaeologists of color (Goulding and Buckley 1994; Howell 1990; Moser 2007; Reyman 1994; She 2000; Wildensen 1994; Wright 2003:231). By the early 2000s, both the AAA and the American 
Institute for Archaeology incorporated policies against harassment in their codes of ethics (Wright 2003:227). The SAA first issued a Statement on Sexual Harassment and Violence in 2015. In 2016, the SAA amended its Principles of Archaeological Ethics with "Principle No. 9: Safe Educational and Workplace Environments" (Hays-Gilpin et al. 2019; Society for American Archaeology 2020; Wright 2003, 2008).

\section{Quantification: Survey Research}

In the 2010s, a series of survey-based quantitative research studies assessed the precise extent of harassment in archaeology. The first survey to directly include archaeologists-the 2013 Survey of Academic Field Experiences (SAFE13; Clancy et al. 2014)_emerged through biological anthropologist Kathryn Clancy's experience as a blogger on gender issues in research:

Because of this blog, I get a lot of email and contact with women who have stories to tell about their experiences in science. I have heard enough of these by now, stories of harassment and assault, of belittling and being passed over, of subtle and overt sexism, that I feel it's time to share some of them [Clancy 2012].

The SAFE13 survey was distributed to researchers in multiple field-based disciplines and organized around three core questions:

(1) Did respondents experience harassment and assault at field sites?

(2) If so, who were the targets and perpetrators?

(3) Do field sites have codes of conduct and effective reporting mechanisms?

Survey respondents were recruited through a combination of social media, professional membership lists, snowball sampling, and chain referral. Of the 666 survey respondents, $23.9 \%$ were archaeologists; $72.4 \%$ reported knowledge of harassment and assault at field sites, with $70 \%$ of women respondents and $40 \%$ of men respondents reporting that they had personally experienced harassment; and $26 \%$ of women and $6 \%$ of men reported sexual assault during field research (Clancy et al. 2014:2-5). Additionally, SAFE13 respondents reported that harassment was predominantly perpetrated by other members of the research team rather than by strangers or locals. Women respondents most commonly reported being targeted by superiors (vertical harassment), whereas men respondents commonly reported being targeted by peers (horizontal harassment).

Two studies used membership rosters from archaeology societies (Southeastern Archaeological Conference [SEAC] and the Society for California Archaeology [SCA]) to recruit survey participants, thereby yielding statistically significant results. ${ }^{3}$ Like SAFE13, both studies revealed a high prevalence of both nonphysical harassment and unwanted sexual contact during fieldwork experiences. Both studies also confirmed the general pattern in which women archaeologists experienced more vertical harassment and men archaeologists were more commonly harassed by peers (Meyers et al. 2015, 2018; Radde 2018; VanDerwarker et al. 2018).

The SEAC study also analyzed survey results in relation to career stage and career trajectory, finding that "those who experience either sexual harassment or unwanted contact were overwhelmingly in 'low-status' positions when the incidents occurred," including "undergraduate and graduate students, field techs, and volunteers" (Meyers et al. 2015:32). Of the survey respondents, $12 \%$ reported that harassment had affected their careers, including slowed research trajectories along with changes in jobs and field sites. Notably, many respondents also emphasized that harassment had generated insecurity about their own abilities and their career futures, and many considered leaving the field altogether (Meyers et al. 2015:28). This suggests a connection between harassment and the "leaky pipeline" that reduces diversity among archaeologists.

The study of SCA members-named Gender Equity and Sexual Harassment (GESH) - is the most comprehensive and detailed survey conducted to date, and it confirms the generally high rates of harassment in archaeology. The GESH study found that for both students and professional archaeologists, women were overwhelmingly harassed by men, whereas men were harassed nearly equally by men and women (Radde 2018:238, 241). The GESH results also challenge the perception that 
harassment is more common during archaeological field research, finding that reported harassment "took place in nearly equal proportions in the field, classroom, and laboratory/office across all demographics" (Radde 2018:239).

The GESH study also found that few survivors of harassment or assault reported their experiences. Those who did report indicated that doing so was largely ineffectual. Radde (2018:244) concludes that "our disciplinary culture either does not encourage reporting, that reporting harassment is socially unsanctioned, or that fear of retaliation is a significant factor" (Radde 2018:244). The Acoso sexual en arqueología (ASA) study, a web-based survey on harassment in archaeology in Spain, drew similar conclusions: $89 \%$ of formally reported harassment cases resulted in no consequences to the harasser (Coto Sarmiento et al. 2018:24, 39). The ASA study also confirmed that patterns of harassment documented through U.S.-based studies are equally prevalent in Spain, including the dominant pattern of harassment of junior women archaeologists by men in positions of authority (Coto Sarmiento et al. 2018:22-23).

The GESH study was the first in archaeology to systematically collect and release information about the relationship between race, sexual orientation, and nonbinary gender identity and harassment. Archaeologists of color of all genders reported higher-than-average experiences of both verbal and physical harassment-in fact, professional archaeologists of color reported the highest frequency of physical harassment of any analysis group (Radde 2018:238-239, 252). LGBTQIA+ respondents also reported high frequencies of harassment and were more often harassed by supervisors than by peers (Radde 2018:235, 240, 243, 252).

The first international study of harassment in archaeology was the 2018 Fieldwork Experiences survey, which also found that nonmale archaeologists, nonheterosexual archaeologists, and archaeologists with disabilities were at greater risk for experiencing sexual misconduct (Bradford and Crema 2020). Including respondents from 26 countries across six continents, the survey not only confirmed the high prevalence of harassment documented in other studies but also indicated that the occurrence of sexual misconduct during fieldwork was predicted by the length of the fieldwork and the policies and protocols regarding sexual misconduct. As the length of fieldwork increased, so did the likelihood of sexual misconduct . . . the likelihood of sexual misconduct occurring decreased specifically when participants knew about these policies and protocols before arriving at the site [Bradford and Crema 2020:10].

In Canada, two separate surveys examined archaeologists' experiences with harassment in broader contexts related to equity and intersectionality. Jalbert (2019) used a mixed-methods research design that combined longitudinal data about education and employment in archaeology with an online survey and semistructured interviews. Although cisgender women have long maintained a majority among Canadian archaeology students and graduate funding awards, cisgender men continue to dominate postdoctoral and faculty positions as well as field research permits numerically (Jalbert 2019:151-152). Concurrently, $78 \%$ of cisgender women archaeologists report sexual harassment or other unwanted behaviors, in contrast to only $16 \%$ of cisgender men (Jalbert 2019:177). From follow-up interviews with 17 survey respondents, Jalbert (2019:203) observes that the prevalence of harassment affects all women archaeologists, who "are acutely aware of the potential for inappropriate or violent situations to be perpetrated against them," regardless of whether they had personally experienced harassment.

In 2020, Hodgetts and colleagues released the first phase of analysis of the Equity and Diversity in Canadian Archaeology survey, which queried respondents about five types of negative career experiences: verbal harassment, exploitation, nonsexualized violence, unwanted sexual touching, and sexual violence / sexual assault. The overall rate of negative experiences was incredibly high, with cisgender women more commonly experiencing harassment and cisgender men more commonly experiencing labor exploitation and nonsexual violence. Consistent with previous studies, negative experiences were most common at early career stages: 
"Some senior archaeologists may see the discipline getting better, in part, because they are no longer in vulnerable positions ... . [but] unacceptable behaviours are still widespread" (Hodgetts et al. 2020:40). Future analyses will focus on intersecting identities, especially related to ethnic diversity, nonbinary genders, and LGBTQIA+ archaeologists.

Research is continuing. At the time of this writing, three web-based surveys are currently underway or not yet reported (Colegio de Arqueólogas y Arqueólogos de Chile 2020; Landward Research 2020; Nakhai 2014). The published surveys reviewed here conclusively demonstrate that harassment is pervasive in archaeology and that it follows specific patterns. Archaeologists are typically harassed by other archaeologists, usually members of their own research team or workplace group. Women experience harassment more frequently than men, but the frequency of men reporting harassment is also disturbingly high. Women are more commonly targeted by men superiors, whereas men archaeologists are more commonly targeted by peers of both genders. Archaeologists of color, LGBTQIA+ archaeologists, and archaeologists with disabilities are disproportionately targeted. Although archaeological field research poses specific challenges, harassment is also pervasive in classroom, laboratory, office, and conference settings. Specific organizational factors, such as the presence or absence of codes of conduct and reporting mechanisms, are correlated with the occurrence of harassment.

\section{Beyond the Numbers: Interviews}

Systematic interview studies contribute qualitative and longitudinal information about patterns of harassment in archaeology and the disciplinary attitudes and organizational factors that allow it to occur. These studies "make visible the shortcomings of policies and procedures" (Collective Change 2019:13) intended to address harassment in archaeology.

In Australia, the On Disciplinary Culture study (Moser 2007) located harassment in archaeology within a field research culture "that valorizes everything connected with the active (and actively) heterosexual male, or perhaps more specially, everything connected with a certain type of masculinity" (Moser 2007:259). Moser's analysis found that senior archaeologists often evaluated other archaeologists' professional skills based on their social fit with existing disciplinary culture (Moser 2007:247). Consequently, both men and women must be prepared to become "one of the blokes" to succeed, including going along with-rather than objecting to-gender discrimination and harassment (Moser 2007:259). Although Moser's analysis of these findings focused primarily on gender, her finding that "social fit" was a key evaluative criterion for archaeologists has significant ramifications for harassment and bias related to race, ethnicity, class, disability, and native language.

The Signaling Safety study (Nelson et al. 2017) presented qualitative interview data collected as part of the SAFE13 survey (Clancy et al. 2014). Twenty-six respondents to SAFE13 were selected in order to include a diversity of field experience narratives. The interviewees' responses were analyzed using thematic analysis - a method to detect and explore patterns within qualitative data. The study detected a clear association between participants' field experiences and the presence or absence of rules, as well as the mechanisms for enforcement of those rules (Nelson et al. 2017:713). Overall, field settings were grouped into three categories: Green (clear rules that were enforced, with consequences for violations), Yellow (rules were present, but they were not enforced), and Red (ambiguous or no rules, with an absence of consequences). Green fieldwork contexts had very low incidences of harassment. Living and working conditions were intentional and safe, and directors anticipated problems and created avenues for both conversations and reporting. Additionally, "everyone was enculturated to look out for each other," and "field site directors strongly demonstrated that they valued every member of the research team" (Nelson et al. 2017:716). In contrast, both Yellow and Red field research contexts were strongly correlated with harassment and sexual assault (Nelson et al. 2017:717). The researchers concluded that

the permissive and ambiguous nature of Red and Yellow contexts protects perpetrators not only from repercussions but also from 
forming or confronting the conscious awareness of the pervasive and long-term effects of their actions for individual targets, bystanders, and the intellectual landscape of our scientific community [Nelson et al. 2017:718].

Thematic analysis of interviewees' responses also identified patterns in fieldwork harassment, including (1) gendered divisions of labor; (2) behavioral hazing, including exposure to pornographic images, deprivation of necessities (bathroom access, food, and water), and unnecessary physical challenges not related to the work being performed; and (3) discounting the accomplishments of female researchers. These all contributed to establishing in-group/out-group dynamics, generating feelings of alienation and distress among the affected fieldworkers. Interviewees "expressed feeling 'vulnerable,' 'powerless,' 'not in control,' 'isolated,' or like 'prey"' (Nelson et al. 2017:714).

The professional narratives collected through the Signaling Safety interviews enabled analysis of the ways in which hostile environments and negative experiences influenced careers. Difficulty accessing data, career stalling, lateral career moves, and career abandonment were common among those who had been victimized by harassment during fieldwork. Nelson and colleagues also observed:

Interview participants also described considerable cognitive and psychological burdens. The continual processing and decision making that goes into negotiating a hostile work environment and maintaining employment can be exhausting and lead to a reduction in mental and physical health [Nelson et al. 2017:715].

The Diversity, Identity, and Oppression in the Production of Archaeological Knowledge study (Heath-Stout 2019) included interviews of 72 archaeologists recruited through snowball sampling and social media about their career trajectories, research interests, and experiences of gender, race, and sexuality in the discipline. The archaeologists surveyed were in three subfields: Latin American prehistoric archaeology, Mediterranean prehistoric archaeology, and historical archaeology of the Americas. The results of the survey were analyzed using methods based on grounded theory, an approach that develops interpretations based on the words of the interviewees (Heath-Stout 2019:248). These methods allowed Heath-Stout to pay particular attention to the interrelationship between gender diversity, race, ethnicity, class, and disability.

Like Signaling Safety and related surveys, Heath-Stout's analysis showed that harassment is prevalent in archaeology and that women, archaeologists of color, and LGBTQIA+ archaeologists are disproportionately targeted by harassers, further contributing to the lack of diversity among archaeologists. As one interviewee recounted,

And so I kind of got pushed out of the region, because of the uncomfortableness of stuff. People talk about how you have one bad experience in this thing and then all of a sudden now it completely changes the trajectory of your career. I mean, I definitely think that happened to me [Heath-Stout 2019:277].

Heath-Stout concludes:

Many of my interviewees left field projects, regions, or subfields in order to avoid colleagues who had harmed them. . . . All of this adds up to a chaotic network where women and other marginalized people move among regions and projects in search of safety, but there are no reliably or predictably safe destinations [Heath-Stout 2019:267, 269].

In addition, Heath-Stout's interviewees reveal how cultural norms in archaeological research foster harassment: "harassers are not always the obviously-creepy men: women are in danger of harassment from people they consider good friends. These harassers often use alcohol and the party culture of field schools to evade responsibility for their actions" (Heath-Stout 2019:282). Furthermore, harassment in archaeology is learned intergenerationally: "Several interviewees discussed the ways that senior men attempted to bring them into a culture of harassing women" (Heath-Stout 2019:283). This includes cisgender junior men who are asked to participate in harassing behavior and banter as well as queer women who were 
pressured by project directors to "participate in discussions of the sexual appeal of other women on the project" (Heath-Stout 2019:283). This intergenerational pressure "creates a chilly climate not only for its direct targets but also for men and queer women who refuse to participate in harassing colleagues" (Heath-Stout 2019:283).

One of the most significant findings of HeathStout's interviews is that harassment places a "cognitive burden" on those who are targeted: "Marginalized archaeologists must [strategize] how to navigate careers in a discipline where they are subject to microaggressions, bullying and harassment, and systematic injustices" (Heath-Stout 2019:289). Heath-Stout's research contributes new understanding to the "leaky pipeline" phenomenon observed earlier by gender equity studies: students and junior colleagues may leave archaeology not only because harassment directly excludes them from professional opportunities but also because the cognitive burden generated by discrimination and harassment interferes with their professional training and advancement.

Leighton's (2020) Myths of Meritocracy ethnographic and interview study returns to the question of "social fit" first identified by Moser in 2007. Through analysis of 96 formal recorded interviews with archaeologists as well as participant observation in archaeology classrooms, field sites, and conferences, Leighton found that "performative informality" is a core value in archaeology that obscures actual gender and class hierarchies in archaeological research. Being likeable, having fun, drinking heavily, engaging in boundary-pushing verbal and physical humor, and developing intimate friendships as well as sexual or romantic relationships with other archaeologists are all core practices of the archaeology work cultures that Leighton observed. Leighton suggests that "it is also quite likely that a culture of fun, friendship, and informality allows intentional bullying, harassment, or discrimination to be masked, denied, or downplayed" (Leighton 2020:452). Leighton further challenges archaeologists' tolerance for the prevalent pattern of romantic/sexual relationships between professors and students in archaeology:
A certain amount of willful blindness is required to ignore the ramifications of a professor entering into multiple sexual relationships with undergraduate and graduate students, no matter how consensual. . . . The impact of senior men pursuing junior women extends far beyond the individuals involved because it actively discourages women from seeking out or taking advantage of professional opportunities for fear of being unable to say "no" to sexual advances [Leighton 2020:451-452].

Most recently, Colaninno and colleagues (2020) identified concrete actions that can be taken to address the causes of harassment documented by Moser, Nelson and colleagues, Health-Stout, and Leighton. Noting that "aspiring archaeologists may experience their first occurrence of sexual harassment, assault, and violence as undergraduates or graduate students enrolled at field school" (Colannino et al. 2020:112), they propose adapting the results of the National Academies of Sciences, Engineering, and Medicine consensus report (Johnson et al. 2018) to create inclusive, harassment-free learning environments for archaeologists in training. Reinforcing findings of previous studies, they emphasize the key role that field directors play and argue that it is time "for our discipline to rethink the traditional structure of having a single field director" to foster greater "collective responsibility in overseeing the climate and culture" of archaeological research environments (Colannino et al. 2020:117).

\section{Grassroots Action}

Throughout the 2010s, a number of projects were undertaken to collect and highlight survivors' testimonies to "humanize the statistics" (Collective Change 2019:13). A survivor's decision whether or not to share their experiences, and in what format and context, is a personal one. Archaeologists who have experienced harassment and assault should never be pressured to share their stories.

Professional conferences have been a major focal point for testimonials and activism, perhaps because conferences themselves are events where junior and marginalized archaeologists are especially vulnerable. At the 2016 and 2017 
SAA Annual Meetings, Meagan Thies-Sauder and Ashley Jones organized forum discussions on sexual harassment in archaeology. Both events were sponsored by the SAA Women in Archaeology Interest Group. Each forum was preceded by a 15-minute slideshow that amplified crowdsourced messages about how archaeologists can take responsibility for ending harassment in our field. In 2019, The Collective Change, a group of North American archaeologists, organized and sponsored a series of \#MeTooInArchaeology conference sessions, in which panelists readwithout commentary- "anonymized narratives of sexual misconduct, harassment, and violence" (Collective Change 2019:12). These stories generated intense emotional responses among many attendees, highlighting the importance of providing support services at future events where stories of harassment and assault are recounted in detail.

At the 2018 European Archaeology Association conference in Barcelona, activists papered the conference hallways with posters presenting results of the ASA study (Coto Sarmiento et al. 2018:24, 39), as well as leaving open spaces for conference attendees to anonymously post accounts of their own experiences. Also in Europe, the association Archéo-Éthique (Ethical Archaeology) commissioned the visual art project Archéo-Sexisme, in which anonymous testimonies were illustrated by artists and exhibited in institutions and at conferences (Archéo-Sexisme 2020).

In recent years, open letters, blog posts, workshop discussions, and newsletter articles have drawn specific attention to aspects of harassment that have not received as much attention in research studies. Archaeology blogger RocksMacqueen (2018) discusses the prevalence of harassment at archaeology conferences; quid pro quo harassment related to access to data or collections; and harassment and discrimination based on family status, especially women being demeaned or excluded for getting married or having children. Rocks-Macqueen also emphasizes that although the "senior man-junior woman" harassment pattern is most common, there are also cases of senior women harassing junior colleagues (both cross-gender and same-gender) as well as of junior men harassing senior women, especially in educational settings.

On the blog the Overdressed Archaeologist, van der Vaart-Verschoof (2019) writes specifically about the trials faced by femininepresenting archaeologists:

I've had my appearance commented on and my body touched without invitation or provocation, and a senior researcher whom I had never met once asked me about what lingerie I was wearing. . . . I've even been asked if I was having sex with my internship supervisor. . . . When people "joke" that you got an internship/job/good position because of the way you look/dress. . . . More than once I started to doubt my own abilities [emphasis in original].

Another anonymous archaeologist (2016) recounts, "Some days you go to work dreading the heckling you know you are going to receive. .. . Patronizing comments like 'look guys, a woman working, take a picture' and 'you can't work here, you'll have to go get your nails done' are hard to ignore." Blackmore and colleagues (2016:20) note the comparable pressures faced by masculine-presenting women archaeologists: "It was hard to ignore it [homophobia] when strong women, regardless of their sexuality, were called dykes by male professors."

Grassroots activism on social media has transformed the conversation about harassment in archaeology by bringing attention to emerging and imminent situations in real time. Two prominent examples are (1) the controversy about former University of Alaska Anchorage professor David Yesner's on-site registration at the April 2019 annual meeting of the SAA (Awesome Small Working Group 2019; Flaherty 2019; Grens 2019; Rivera 2019; Wade 2019) and (2) the events at the November 2019 Council for British Archaeology meeting, during which a group of attendees broke into derisive laughter when Danielle Bradford received the Marsh Archaeology Award for her research on sexual misconduct in archaeology (British Broadcasting Corporation 2019). Additionally, student journalists are increasingly playing a significant role in uncovering patterns of harassment and abuse in archaeology in academic settings: a 
recent investigative report by the Harvard Crimson is especially notable for identifying connections between long-term tolerance of faculty-student quid pro quo relationships in archaeology and broader patterns of genderbased discrimination that affect both faculty and students (Bikales 2020).

\section{Conclusion}

And when do we have enough data? It's not like there isn't already a plethora of existing literature attesting to the scope and consequences of these actions [Bradford 2019].

The research conducted to date makes it clear that harassment is epidemic in our field. Harassment damages many archaeologists' careers and drives others out of the field altogether. It has therefore shaped our discipline at a fundamental level, affecting who can practice archaeology, how archaeologists are trained, what research topics are investigated, and how archaeological data is interpreted, published, and cited. It is notable that the studies reviewed for this article reflect the experiences of currently practicing archaeologists: people like me, who stayed in archaeology despite experiencing and witnessing harassment. We do not yet know how many people left archaeology altogether because of harassment.

There are still important gaps in current research, especially regarding the experiences of LGBTQIA+ archaeologists, archaeologists of color, and archaeologists with disabilities. Several surveys collected responses from archaeologists of color and LGBTQIA+ archaeologists but excluded these identity categories from published analysis in order to protect participants' anonymity. The low number of responses from nonwhite, noncisgender, and nonheterosexual archaeologists reflects broader structures of exclusion in archaeology, and more inclusive research designs are needed to ensure that their experiences do not continue to be underrepresented in research on harassment.

As Doug Rocks-Macqueen (personal communication 2020) emphasizes, "It really does not matter if the frequency of harassment in archaeology is $5 \%$ or $50 \%$; the results are so horrific. Even if we had only $1 \%$, it is too high of a number." Fortunately, there are pathways for positive change. Evidence-based interventions can significantly decrease harassment and reduce adverse outcomes for survivors. Some are already being adopted in archaeology with promising results. The next article, "Disrupting Cultures of Harassment in Archaeology" (Voss 2021), turns to these solutions.

\section{Coda: Where to Go for Support}

It can be overwhelming to learn about the pervasiveness of harassment in archaeology. For survivors and witnesses, it can be both validating and unsettling to learn that our negative experiences are part of a discipline-wide pattern. Whether you are a survivor, have witnessed harassment and sexual assault, or know someone who has, you are not alone. Support is available. If you are not sure where to start, the Rape, Abuse \& Incest National Network (RAINN) provides free and confidential support to survivors and to those who care about them. Support is available 24 hours a day, 7 days a week by phone (800-656-4673) and through live chat: https://www.rainn.org/. En español, llame al (800-656-4673) a la Línea de Ayuda Nacional Online de Asalto Sexual o comuníquese a través de la opción "Chat Ahora": https://www. rainn.org/es.

Acknowledgments. This essay is dedicated to all survivors of harassment in archaeology. I am especially thankful to those who have conducted research on harassment in archaeology and to activists and advocates throughout archaeology's history. I began to write this article series during involvement in anti-harassment committees and programs in my workplace. My thanks to many colleagues, students, staff, and administrators - too numerous to list by name here-who shared their expertise and experiences, and to Danielle J. Bradford, Kathryn Clancy, Deb Cohler, Carol Colaninno, Kathy Coll, Laura Daly, Maura Finkelstein, Mark Hauser, Kelley Hays-Gilpin, Laura Heath-Stout, Lochlann Jain, Caren Kaplan, Kristina Killgrove, Hugh D. Radde, Doug Rocks-Macqueen, Maureen S. Meyers, Sarah Rowe, Dawn Rutecki, Megan Thies-Sauder, Sasja van der VaartVerschoof, and seven anonymous reviewers who provided thoughtful feedback on earlier drafts. Special thanks to Lynn Gamble for her support and guidance throughout the publication process, to Laura Daly and Alicia Gorman for copyediting, and to Grace Alexandrino Ocaña for the Spanish translation of the abstract. The Stanford Archaeology Center Director's Fund generously funded Gold Open Access for this article. 
The author is not aware of any financial interests or affiliations that pose a conflict of interest with the content of this article.

Data Availability Statement. This study is based on analysis of published research, survivor accounts, news reports, and online resources; all data is available through the sources listed in the References Cited section.

\section{Notes}

1. Not all people affected by harassment prefer the widely used term "survivor," which can give the false impression that harassment was an event that occurred in the past rather than an ongoing reality that many archaeologists cope with on a daily basis. Alternative terms include "target," "victim," and "person affected by harassment or sexual violence."

2. Lesbian, Gay, Bisexual, Transgender/Transsexual/ Trans, Queer, Intersex, Asexual, plus nonbinary, gender nonconforming, and many others whose actual or perceived gender and/or sexuality does not conform to sanctioned norms, along with allies of LGBTQIA+ individuals and communities.

3. Survey questions and responses for the SEAC and GESH surveys are publicly available at https://vanderwarker. anth.ucsb.edu/research/databases.

\section{References Cited}

Anonymous

1994 The Female Anthropologist's Guide to Academic Pitfalls. Reprinted from 1971 Anthropology Newsletter 12(4):8-9. In Equity Issues for Women in Archaeology, edited by Sarah M. Nelson, Margaret C. Nelson, and Alison Wylie, pp. 5-6. Archaeological Papers No. 5. American Anthropological Association, Washington, DC.

2016 The Secret Life of an Archaeologist: Soil in Your Sandwiches and Sexism on Sites. Guardian, April 25. https://www.theguardian.com/commentisfree/2016/ apr/25/secret-life-archaeologist-soil-sandwiches-sexismsites, accessed November 19, 2020.

Archéo-Sexisme

2020 Archéo-Sexisme. Electronic document, https://www. wax-science.fr/archeo-sexisme/, accessed January 15, 2020.

Association of Black Anthropologists

2020 Association of Black Anthropologists: ABA's History and Purpose. Electronic document, http://aba. americananthro.org/abas-history-and-purpose/, accessed August 27, 2020.

Awesome Small Working Group

2019 \#MeToo in Archaeology. SAA Archaeological Record 19(4):16-21.

Bikales, James S.

2020 Protected by Decades-Old Power Structures, Three Renowned Harvard Anthropologists Face Allegations of Sexual Misconduct. Harvard Crimson, May 29. https://www.thecrimson.com/article/2020/5/29/harvardanthropology-gender-issues/, accessed August 17, 2020.

Blackmore, Chelsea, Leslie Drane, Richard Baldwin, and David Ellis

2016 Queering Fieldwork: Difference and Identity in Archaeological Practice. SAA Archaeological Record 16(1):18-23.
Bradford, Danielle

2019 Sexual Harassment in Archaeology by Dani Bradford @ anthroqveer. CIFA Equality and Diversity Group. Electronic document, https://equalityanddiversitygroup. wordpress.com/2019/03/11/sexual-harassment-in-archaeologyby-dani-bradford-anthroqveer/, accessed January 30, 2020.

Bradford, Danielle J., and Enrico R. Crema

2020 Risk Factors for the Occurence of Sexual Misconduct during Archaeological and Anthropological Fieldwork. Manuscript on file, McDonald Institute for Archaeological Research, University of Cambridge, Cambridge.

Bradford, Danielle, Charlotte L. R. Payne, and Enrico Crema

2019 "How can we make fieldwork safer?" Tweets presenting images and text from a poster paper presented at Faculty Staff Misconduct Conference, (June 30-July 2, 2019, Madison, Wisconsin). Tweeted July 1, 2019. https://twitter.com/anthroqveer/status/11458016110774 10822, accessed January 30, 2020.

British Broadcasting Corporation

2019 Cambridge Sexual Harassment Researcher "Laughed At by Men," November 25. https://www.bbc. com/news/uk-england-cambridgeshire-5053772, accessed November 23, 2020.

Browman, David L.

2013 Cultural Negotiations: The Role of Women in the Founding of Americanist Archaeology. University of Nebraska Press, Lincoln.

California Department of Fair Employment and Housing

2020 Sexual Harassment FAQs: What Is Sexual Harassment? Electronic document, https://www.dfeh.ca.gov/ resources-2/frequently-asked-questions/employmentfaqs/sexual-harassment-faqs/, accessed February 6, 2020.

Clancy, Kathryn B. H.

2012 From the Field: "Hazed" Tells Her Story of Harassment. KateClancy.com (blog), January 30. http:/ kateclancy.com/from-the-field-hazed-tells-her-story-ofharassment/, accessed February 11, 2020.

2018 Transcript of My Oral Testimony from February 27th Congressional Hearing on Sexual Misconduct in the Sciences. KateClancy.com (blog), February 27. https://kateclancy.com/2018/02/, accessed February 11, 2020.

Clancy, Kathryn B. H., Robin G. Nelson, Julienne N. Rutherford, and Katie Hinde

2014 Survey of Academic Field Experiences (SAFE): Trainees Report Harassment and Assault. PLOS ONE 9(7):e102172. DOI:10.1371/journal.pone.0102172.

Colaninno, Carol E., Shawn P. Lambert, Emily L. Beahm, and Carl G. Drexler

2020 Creating and Supporting a Harassment- and AssaultFree Field School. Advances in Archaeological Practice $8: 111-122$

Colegio de Arqueólogas y Arqueólogos de Chile

2020 Encuesta acoso sexual en el ámbito laboral archaeológico. Electronic document (interactive survey), https:/ docs.google.com/forms/d/e/1FAIpQLSfMFCs_hmK4 WMX1aeox2lmHhJVRKh9_5eUEVar84s7e1TbfeA/ viewform, accessed February 27, 2020

Collective Change, The

2019 \#MeToo in Archaeology. SAA Archaeological Record 19(4):12-15.

Coto Sarmiento, María, Lara Delgado Anés, Lourdes López Martinez, Jesús Martín Alonso, Ana Pastor Pérez, Apen Ruíz Martínez, and María Yubero Gómez

2018 Informe: Acoso sexual en arqueología (ASA). Electronic document, https://www.researchgate.net/profile/ 
Ana_Pastor_Perez2/publication/339181406_Informe Acoso_sexual_en_Arqueologia_Espana/links/5e $42 \mathrm{f} 74$ a299bf1cdb91fd26d/Informe-Acoso-sexual-en-Arqueo logia-Espana.pdf, accessed February 27, 2020.

Flaherty, Colleen

2019 Archaeology Group Faces Backlash over How It Handled Known Harasser's Attendance at Meeting. Inside Higher Ed, April 15. Electronic document, https://www.insidehighered.com/news/2019/04/15/ archaeology-group-faces-backlash-over-how-it-handledknown-harassers-attendance, accessed December 3, 2019.

Franklin, Maria, Justin P. Dunnavant, Ayana Omilade Flewellen, and Alicia Odewale

2020 The Future Is Now: Archaeology and the Eradication of Anti-Blackness. International Journal of Historical Archaeology 24:753-677.

Goulding, Megan, and Kristal Buckley

1994 Training and Working Environments in Archeology: Victoria, Australia. In Equity Issues for Women in Archaeology, edited by Sarah M. Nelson, Margaret C. Nelson, and Alison Wylie, pp. 43-46. Archaeological Papers 5. American Anthropological Association, Washington, DC. Grens, Kerry

2019 Archaeologists Ask Society for Harassment Policy Change. The Scientist, April 16. https://www.the-scientist. com/news-opinion/archaeologists-ask-society-for-harassmentpolicy-change-65745?fbclid=IwAR15Y3zpyH79BrsS0SdQ Vg8b_cdU6nVVXgG4THM5bwQu_9vDsVRbT7YYIDg, accessed November 19, 2020.

Harrison, Ira E.

1987 The Association of Black Anthropologists: A Brief History. Anthropology Today 3(1):17-21.

Hays-Gilpin, Kelley, Meagan Thies-Sauder, Catherine Jalbert, Laura Heath-Stout, Heather Thakar, Kenneth Aitchison, Jon Driver, Kisha Supernant, and Amber M. VanDerwarker

2019 Changing Our Professional Culture of Apathy and Creating Safety in Archaeology. SAA Archaeological Record 19(4):8-11.

Heath-Stout, Laura Ellen

2019 Diversity, Identity, and Oppression in the Production of Archaeological Knowledge. PhD dissertation, Department of Anthropology, Boston University, Boston.

Hodgetts, Lisa, Kisha Supernant, Natasha Lyons, and John R. Welch

2020 Broadening \#MeToo: Tracking Dynamics in Canadian Archaeology through a Survey on Experiences within the Discipline. Canadian Journal of Archaeology 44:20-47.

Howell, Nancy

1990 Surviving Fieldwork: A Report of the Advisory Panel on Health and Safety in Fieldwork, American Anthropological Association. Special Publication No. 26. American Anthropological Association, Washington, DC.

Jalbert, Catherine L.

2019 Archaeology in Canada: An Analysis of Demographics and Working Conditions in the Discipline. $\mathrm{PhD}$ dissertation, Department of Archaeology, Memorial University of Newfoundland, St. John's.

Johnson, Paula A., Sheila E. Widnall, and Frazier F. Benya (editors)

2018 Sexual Harassment of Women: Climate, Culture, and Consequences in Academic Sciences, Engineering, and Medicine. National Academies Press, Washington, DC.
Lamb, Daniel S.

1906 The Story of the Anthropological Society of Washington. American Anthropologist 8:564-579.

Landward Research

2020 Profiling the Profession 2020. Electronic document, https://profilingtheprofession.org.uk/, accessed November 30, 2020.

Leighton, Mary

2020 Myths of Meritocracy, Friendship, and Fun Work: Class and Gender in North American Academic Communities. American Anthropologist 122:444-458.

Levine, Mary Ann

1994 Presenting the Past: A Review of Research on Women in Archaeology. In Equity Issues for Women in Archaeology, edited by Sarah M. Nelson, Margaret C. Nelson, and Alison Wylie, pp. 23-36. Archaeological Papers No. 5. American Anthropological Association, Washington, DC.

Mahmood, Cynthia K.

2009 India's Shame: The Personal Ordeal of Cynthia Mahmood. Sikh Chic (blog), April 29. http://sikhchic. com/article-detail.php?cat $=21 \& i d=817$, accessed January 6, 2020.

Meyers, Maureen S., Tony Boudreau, Stephen Carmody, Victoria Dekle, Elizabeth Horton, and Alice Wright

2015 Preliminary Results of the SEAC Sexual Harassment Survey. Horizon and Tradition 57(1):19-35.

Meyers, Maureen S., Elizabeth T. Horton, Edmond A. Boudreaux, Stephen B. Carmody, Alice P. Wright, and Victoria G. Dekle

2018 The Context and Consequences of Sexual Harassment in Southeastern Archaeology. Advances in Archaeological Practice 6:275-287.

Moser, Stephanie

2007 On Disciplinary Culture: Archaeology as Fieldwork and Its Gendered Associations. Journal of Archaeological Method and Theory 14:235-263.

Nakhai, Beth A.

2014 Survey on Field Safety: Middle East, North Africa, and the Mediterranean Basin. Electronic document, https://bibleinterp.arizona.edu/opeds/2014/09/nak38800, accessed November 23, 2020.

National Academies of Sciences, Engineering, and Medicine

2018 Sexual Harassment of Women: Climate, Culture, and Consequences in Academic Sciences, Engineering, and Medicine. Electronic document, https://sites. nationalacademies.org/cs/groups/shstudysite/documents/ webpage/shstudy_187268.pdf, accessed January 27, 2020.

Nelson, Sarah Milledge, and Margaret C. Nelson

1994 Conclusion. In Equity Issues for Women in Archaeology, edited by Sarah M. Nelson, Margaret C. Nelson, and Alison Wylie, pp. 229-235. Archaeological Papers No. 5. American Anthropological Association, Washington, DC.

Nelson, Robin G., Julienne N. Rutherford, Katie Hinde, and Kathryn B. H. Clancy

2017 Signaling Safety: Characterizing Fieldwork Experiences and Their Implications for Career Trajectories. American Anthropologist 119:710-722.

Radde, Hugh D.

2018 Sexual Harassment among California Archaeologists: Results of the Gender Equity and Sexual Harassment Survey. California Archaeology 10:231-255.

Reyman, Jonathan E.

1994 Gender and Class in Archeology: Then and Now. In 
Equity Issues for Women in Archaeology, edited by Sarah M. Nelson, Margaret C. Nelson, and Alison Wylie, pp. 83-90. Archaeological Papers No. 5. American Anthropological Association, Washington, DC.

Rivera, Daniella

2019 Open Letter Gathers 1,800-Plus Signatures Asking Organization to Bar Ex-UAA Professor. KTVA.com, April 16. Electronic document, https://web.archive.org/ web/20190416092343/https://www.ktva.com/story/ 40311625/open-letter-gathers-1800plus-signaturesasking-organization-to-bar-exuaa-professor, accessed December 4, 2019.

Rocks-Macqueen, Doug

201891 Stories of Archaeology. Doug's Archaeology: Investigating the Profession and Research (blog), April 14. https://dougsarchaeology.wordpress.com/ 2018/04/14/91-stories-of-archaeology/, accessed February 5, 2020.

Ross, Karen

2015 "No Sir, She Was Not a Fool in the Field": Gendered Risks and Sexual Violence in Immersed Cross-Cultural She Fieldwork. Professional Geographer 67:180-186.

2000 Sex and a Career. World Archaeology 32:166-172. Society for American Archaeology

2020 Ethics in Professional Archaeology. Electronic document, https://www.saa.org/career-practice/ethicsin-professional-archaeology, accessed December 15, 2020.

Tomásková, Silvia

2008 History of COSWA: Beginnings, Ruptures, and Continuities. SAA Archaeological Record 8(4):8-11.

van der Vaart-Verschoof, Sasja

2019 \#Metoo-A Woman in Academia and Archeology. Overdressed Archeologist (blog), April 6. http:// vandervaart-verschoof.com/metoo-a-woman-in-acade mia-archeology/, accessed January 30, 2020.

VanDerwarker, Amber M., Kaitlin Brown, Toni Gonzalez, and Hugh D. Radde

2018 The UCSB Gender Equity Project: Taking Stock of Mentorship, Equity, and Harassment in California Archaelogy through Qualitative Survey Data. California Archaeology 10:131-158.

Voss Barbara L. 2021. Disrupting Cultures of Harassment in Archaeology: Social-Environmental and Trauma-
Informed Approaches to Disciplinary Transformation. American Antiquity 86, in press.

Wade, Lizzie

2019 \#MeToo Controversy Erupts at Archaeology Meeting. Science, April 15. https://www.sciencemag.org/ news/2019/04/metoo-controversy-erupts-archaeologymeeting, accessed December 3, 2019.

Wildensen, Leslie E.

1994 The Status of Women in Archeology: Results of a Preliminary Survey. Reprinted from 1980 Anthropology Newsletter 21(5):5-8. In Equity Issues for Women in Archaeology, edited by Sarah M. Nelson, Margaret C. Nelson, and Alison Wylie, pp. 65-71. Archaeological Papers No. 5. American Anthropological Association, Washington, DC.

Wright, Rita P.

2003 Gender Matters-A Question of Ethics. In Ethical Issues in Archaeology, edited by Larry J. Zimmerman, Karen D. Vitelli, and Julie Hollowell-Zimmer, pp. 225-237. AltaMira, Walnut Creek, California.

2008 Sexual Harassment and Professional Ethics. SAA Archaeological Record 8(4):27-30.

Wylie, Alison

1993 Workplace Issues for Women in Archaeology: The Chilly Climate. In Women in Archaeology: A Feminist Critique, edited by Hilary du Cros and Laurajane Smith, pp. 245-260. Department of Prehistory, Australian National University, Canberra, Australia.

1994a The Trouble with Numbers: Workplace Climate Issues in Archaeology. Abstracted from Women in Archaeology: A Feminist Critique, edited by Hilary du Cros and Laurajane Smith, Australian National University Press, 1993. In Equity Issues for Women in Archaeology, edited by Sarah M. Nelson, Margaret C. Nelson, and Alison Wylie, pp. 65-71. Archaeological Papers No. 5. American Anthropological Association, Washington, DC.

1994b Introduction. In Equity Issues for Women in Archaeology, edited by Sarah M. Nelson, Margaret C. Nelson, and Alison Wylie, pp. 1-4. Archaeological Papers No. 5. American Anthropological Association, Washington, DC.

Submitted October 10, 2020; Revised December 4, 2020; Accepted December 8, 2020 